\title{
COMPARATIVE STUDY ON PERFORMANCE OF CEMENT MORTAR ENHANCED WITH CARROT POWDER
}

\author{
Jayachandra \\ Assistant Professor, School of Civil Engineering, REVA University, \\ Bengaluru, Karnataka, India.
}

Sanjith J

Assistant Professor, Department of Civil Engineering, Adichunchanagiri Institute of Technology, Chikkamagaluru, Karnataka, India.

\section{B M Kiran}

Associate Professor, Department of Civil Engineering, Adichunchanagiri Institute of Technology, Chikkamagaluru, Karnataka, India.

\section{Chethan G}

Assistant Professor, Department of Civil Engineering, Adichunchanagiri Institute of Technology, Chikkamagaluru, Karnataka, India.

\begin{abstract}
This study was conducted to investigate the physical and mechanical properties of the cement mortar replaced with carrot powder (CP). To do this cement mortar specimen are formed by replacing the carrot powder in varying percentages, the increasing ratio of the $C P$ affected the compressive strength and flexural strength. It was concluded that $C P$ might be used in cement mortar to replace the cement in certain ratio to make them profitable.
\end{abstract}

Keywords: Carrot Powder, Cement Mortar, Compressive Strength, Flexural strength.

Cite this Article: Jayachandra, Sanjith J, B M Kiran and Chethan G, Comparative Study on Performance of Cement Mortar Enhanced with Carrot Powder. International Journal of Advanced Research in Engineering and Technology, 10(6), 2019, pp. 217-223.

http://iaeme.com/Home/issue/IJARET?Volume $=10 \&$ Issue $=6$

\section{INTRODUCTION}

Carrot is rich in dietary fibre, antioxidants and minerals. Carrot fibre provides high strength, stiffness, toughness and a very smooth finish. The composite made from carrot fibres has a lower density than carbon fibre. The aim of the research used in cement mortar production to replace the cement in certain ratio to make them profitable and lessen their adverse effects on the environment. The total production of vegetables was estimated as 268 million tonnes in the 
world during the year 2011). Vegetables are highly seasonal and available in plenty at particular period of the year. During the season, the price decreases and this can lead to heavy losses for the growers. Also, due to the abundant supply during the season, a glut in the market may result in the spoilage of large quantities. Preservation of these vegetables can prevent the huge wastage and make them available in the off-season at remunerative prices. Carrot is a root vegetable, usually red, white or yellow in colour, with a crisp texture when fresh. The total production of carrot \& turnips was estimated as 35.6 million tonnes in the world during the year 2011. Carrots have a moisture content of $80-90 \%$ at the time of harvest and are seasonal in nature and highly susceptible to moisture loss leading to wilting and loss of fresh appeal. It is processed in many forms, such as chopped, frozen or canned. As a fresh vegetable, carrots are also utilized in many cooking recipes such as soups, sauces and dinner meals. It is a rich source of $\beta$-carotene and contains other vitamins, like thiamine, riboflavin, vitamin B-complex and minerals. It is also an excellent source of calcium pectate; a pectin fibre with significant cholesterol lowering properties. It reduces the chances of high blood pressure stroke.

Carrots are processed into different products including canned products, dehydrated products, fruit juice beverages, candy, preserves, intermediate moisture products and halwa. Tenderness is an important quality attribute for canning. Canning of carrots is done in various forms like diced, halved, quartered or whole. A kheer mix has been prepared from dehydrated carrot, skim milk, sugar and other ingredients. Carrot juice and their blends are one of the popular non-alcoholic beverages and gradual increase in carrot juice consumption has been reported in different countries. Carrot juice can be used with other fruit juices in blended form the different processing techniques and storage of carrot juice have been illustrated by researchers.

\section{MATERIALS AND METHODS}

\subsection{Materials used}

- Cement

- Fine aggregate

- Carrot powder

\subsection{Cement}

It is a binding material, is used in construction that sets and hardens and adheres to other materials to bind them together. The cement used in present work is OPC of 53 grade.

\subsection{Fine Aggregate}

Fine aggregate from a river bed, passing through $4.75 \mathrm{~mm}$ and free from lumps were procured and the crushed granite stone (coarse aggregate) passing through the $20 \mathrm{~mm}$ and $12 \mathrm{~mm}$ were chosen and used in the present work. The fine aggregate falls in zone- 2 was used in present work.

\subsection{Carrot Powder}

Carrot is a biomaterial that are rich in dietary fibre, that is carbohydrates that cannot be digested by our body's enzymes, the carrot fibre extracted from carrot provides high strength, stiffness and smooth surface. 


\section{PROPERTIES OF CARROT POWDER}

1.Carrot powder is very rich in vitamins $\mathrm{A}, \mathrm{B}_{12}$, and the powder is also providing several minerals including calcium (33 mg) Sodium (69 mg) potassium (32 mg), Magnesium (12 mg).

2. Carrots are rich in cellulose and other biological active materials which leads to greater stickiness property, Higher heat resistance and higher toughness and also improves the bond strength of the material.

\subsection{Perpetration of Carrot Powder (CP)}
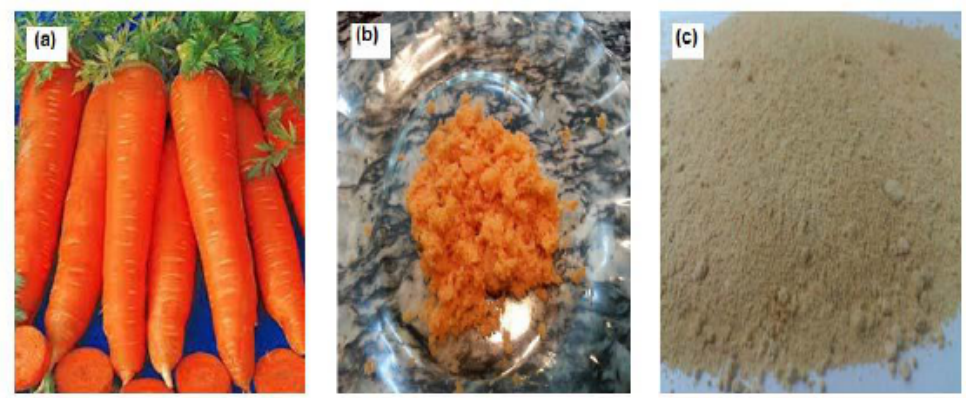

Figure 1 (a) Carrot roots (b) Carrot fibres from processed roots (c) Carrot powder after being processed by ball milling.

Carrot seeds were purchased locally from vegetable supplier. They were Cleaned to remove all foreign matter such as dust, dirt, and stones. The juice was removed from carrot seeds by using machine vegetables; the solid waste from carrot juice is rich in fibre. The percentage limit of fibre content is $30 \%$ fibres which is regarded as a functional fibre source. The carrot fibre was milled for 15 minutes. The carrot powder (CP) was only tested for particle size analysis and surface area to show the effect of milling time on the average particle size and specific surface area. The X-ray Diffraction (XRD) analysis was performed to determine the phases of the produced PC powder samples, the particle size used to measure the particle size distribution for powder used in this study.

\subsection{Mortar Cement Mix}

A mortar specimen of approximately $7.1 \mathrm{~cm} * 7.1 \mathrm{~cm} * 7.1 \mathrm{~cm}$ for compression test and $160 \mathrm{~cm} * 40 \mathrm{~cm} * 40 \mathrm{~cm}$ for flexural test, is casted for $5 \%, 10 \%, 15 \%$ and $20 \%$ carrot powder cement replacement. The specimens were left for setting for three different durations $(7,28$ and 56 days).

For compressive strength test No of cubes $=90$

\begin{tabular}{|c|c|c|c|c|c|}
\hline $\begin{array}{c}\text { \% of carrot } \\
\text { powder }\end{array}$ & 0 & 5 & 10 & 15 & 20 \\
\hline $1: 3$ & 6 & 6 & 6 & 6 & 6 \\
\hline $1: 5$ & 6 & 6 & 6 & 6 & 6 \\
\hline $1: 6$ & 6 & 6 & 6 & 6 & 6 \\
\hline
\end{tabular}

For flexural strength test No of prisms $=90$

\begin{tabular}{|c|c|c|c|c|c|}
\hline $\begin{array}{c}\text { \% of } \\
\text { carrot } \\
\text { powder }\end{array}$ & 0 & 5 & 10 & 15 & 20 \\
\hline $1: 3$ & 6 & 6 & 6 & 6 & 6 \\
\hline $1: 5$ & 6 & 6 & 6 & 6 & 6 \\
\hline $1: 6$ & 6 & 6 & 6 & 6 & 6 \\
\hline
\end{tabular}




\section{RESULTS}

\subsection{Flexural Strength Test Results}

Flexural strength of the mortar prism is high for $0 \%$ carrot powder replaced prisms compared to $5,10,15$ and $20 \%$ replaced prisms.

\subsection{Compressive Strength Test Results}

The compressive strength test value was found that addition of $\mathrm{CP}$ resulted in lower compressive strength of the cube compared to $0 \%$ carrot replaced prism for $1: 3$ mix proportion mortars compressive strength is high.it was observed that 1:3 mix ratio cubes have yielded more strength compared to 1:5 and 1:6 the decrease in strength could be observed in the graph shown below.

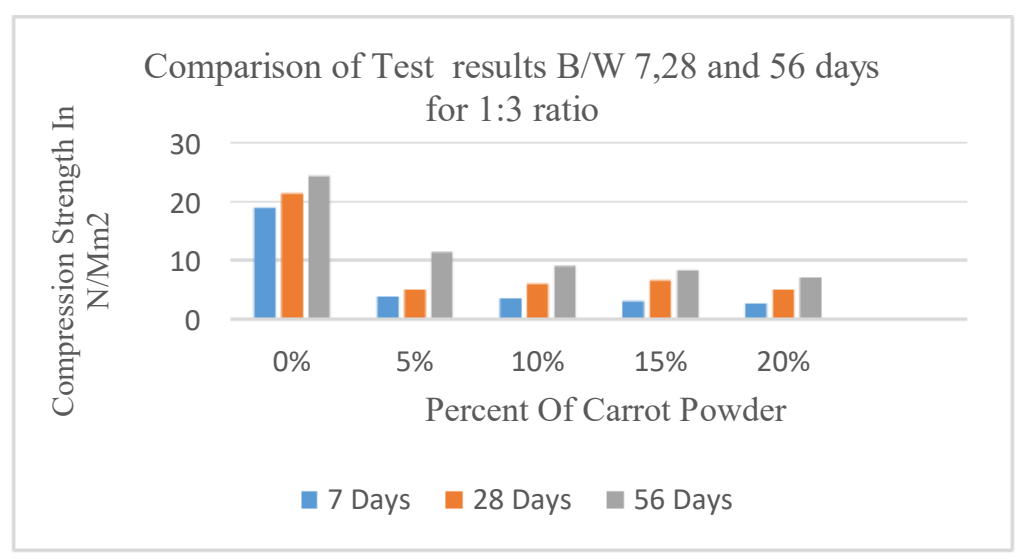

Graph 1: Comparison of compressive strength Test Results B/W 7,28 and 56 days for 1:3 ratio

Discussion: It has been observed from the graph that the compressive strength of the $0 \%$ carrot powder based mortar cube is more, compared to CP replaced mortar cube.

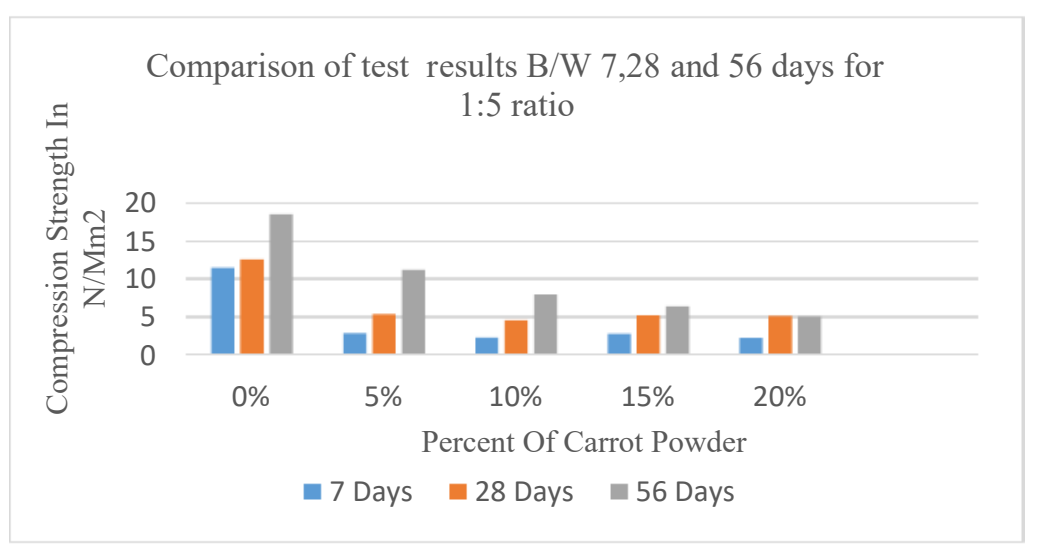

Graph 2: Comparison of compressive strength Test Results B/W 7,28 and 56 days for 1:5

Discussion: It has been observed from the graph that the compressive strength of the $0 \%$ carrot powder based mortar cube is more, compared to CP replaced mortar cube. 
Comparative Study on Performance of Cement Mortar Enhanced with Carrot Powder

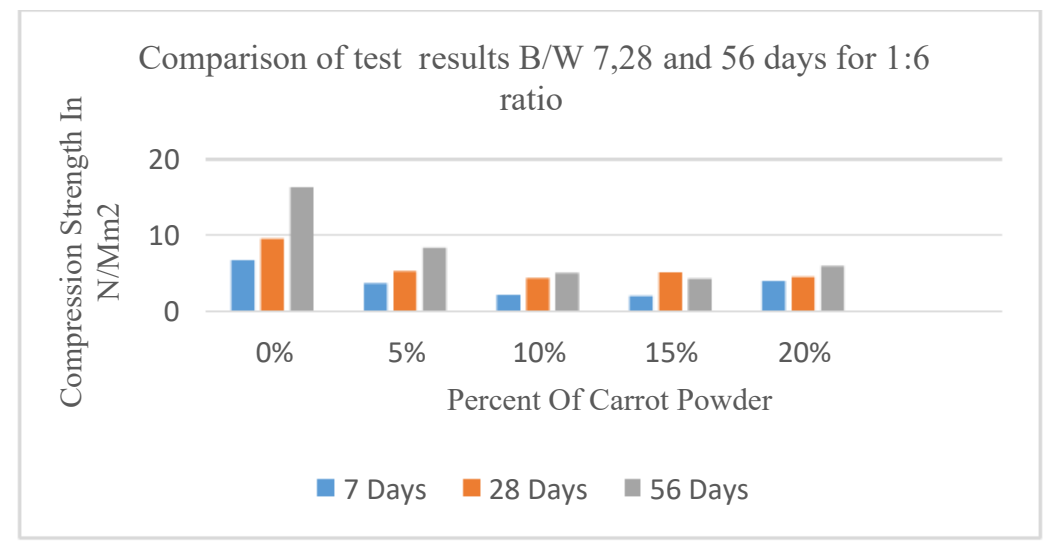

Graph 3: Comparison of compressive strength Test Results B/W 7,28 and 56 days for 1:6

Discussion: it has been observed from the graph that the compressive strength of the $0 \%$ carrot powder based mortar cube is more, compared to CP replaced mortar cube.

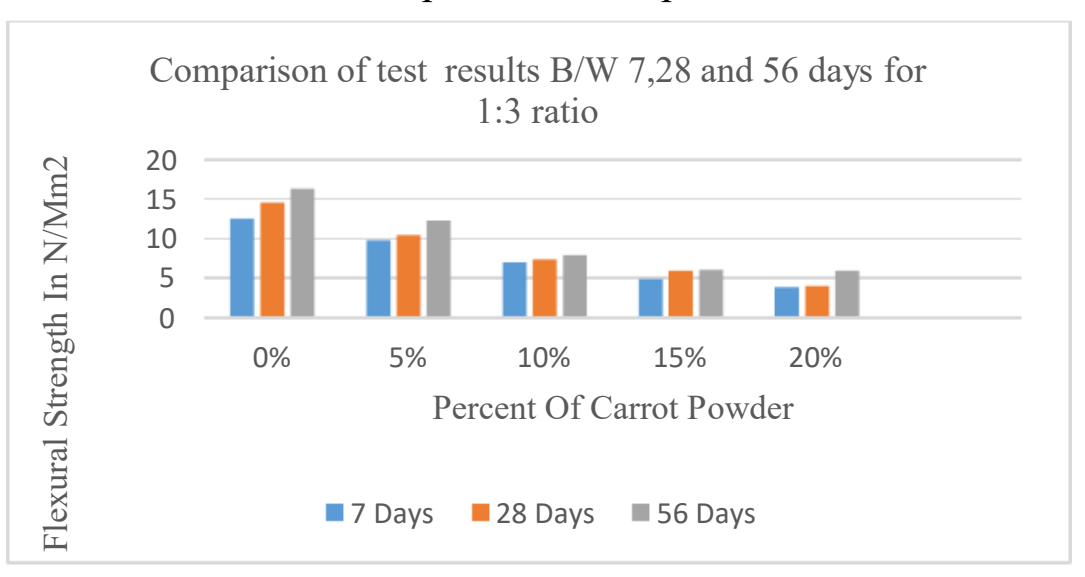

Graph 4: Comparison of flexural strength Test Results B/W 7,28 and 56 days for 1:3

Discussion: The flexural strength of the prism was found to be high for 1:3 mix proportion prisms and the strength achieved by those are comparatively higher than that of 1:5 and 1:6.

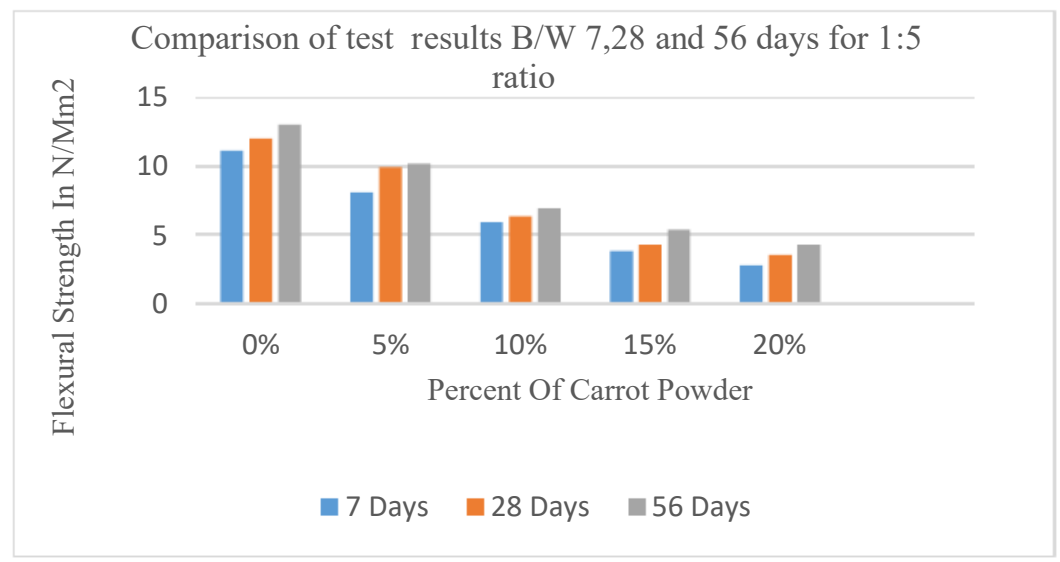

Graph 5: Comparison of flexural strength test results b/w 7,28 and 56 days

Discussion: The flexural strength of the prism was found to be high for 1:3 mix proportion prisms and the strength achieved by those are comparatively higher than that of 1:5 and 1:6. 
Jayachandra, Sanjith J, B M Kiran and Chethan G

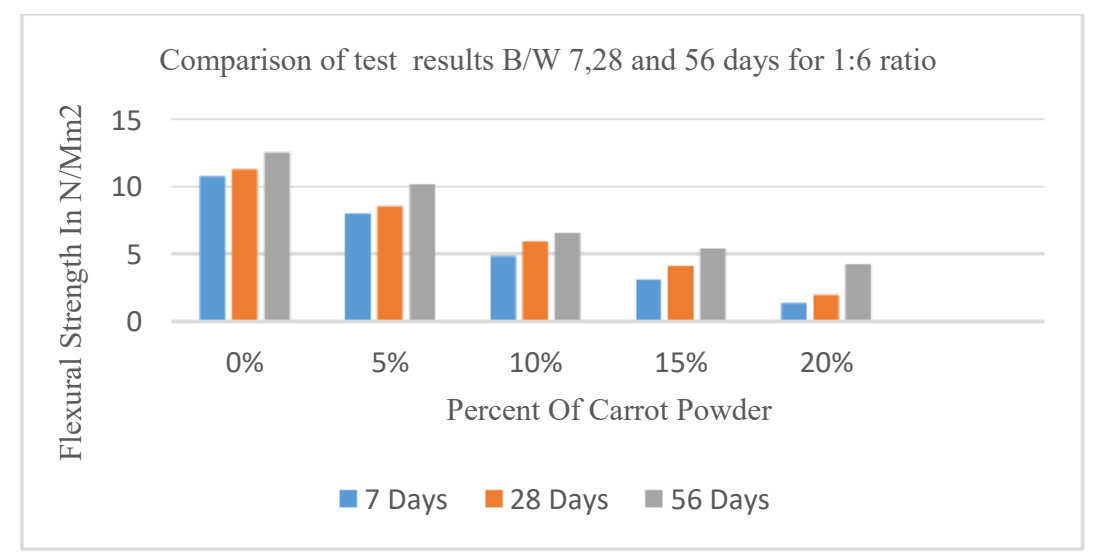

Graph 6: Comparison of flexural strength Test Results B/W 7,28 and 56 days for 1:6 ratio

Discussion: The flexural strength of the prism was found to be high for 1:3 mix proportion prisms and the strength achieved by those are comparatively higher than that of 1:5 and 1:6.

\section{CONCLUSIONS}

The results obtained from the tests are plotted in the graph which concludes that the compressive strength and flexural strength for 1:3 mix proportion $0 \%$ carrot powder replaced mortar cubes are high compared to the cubes replaced with 5, 10, 15 and 20\% of carrot powder in the same way. The 1:3 mix proportion mortar cubes have taken higher values compared to 1:5 and 1:6 mix proportion. Which concludes that compressive strength and flexural strength is more for 1:3 mix proportion mortar cubes.

\section{REFERENCES}

[1] Steve P. 2008 "The future is orange for hi-tech material made from carrots", Press Association.

[2] Vijaya Bhaskar. A and M. Shanmugasundaram (2018), A Study on Strength of Mortar with Multiwalled Carbon Nano Tube as Additive, International Journal of Civil Engineering and Technology, 9(13), 2018, pp. 553-558

[3] Suddell, B. C. and Evans, W. J. 2005. "Natural Fibre Composites in Automotive Applications in Natural Fibers in Biopolymers and Their Biocomposites", Editors A.K. Mohanty, M. Mishra and L.T. Drzal, CRC Press: 231-259.

[4] Mohd Aasif Rasool, Owias Nazir, Mandeep Kaur and Paramveer Singh (2017), Shear Performance of Saturated and Unsaturated Brick Masonry at Different Mortar Grades - An Experimental and Numerical Analysis. International Journal of Mechanical Engineering and Technology, 8(7), 2017, pp. 1411-1416.

[5] Satisha, N. S., Shruthi, C. G., Kiran, B. M., \& Sanjith, J. (2018), Study on Effect of Polypropylene Fibres on Mechanical Properties of Normal Strength Concrete with Partial Replacement of Cement, International Journal of Advanced Research Trends in Engineering and Technology (IJARTET), Vol. 5, Issue 1, January 2018.

[6] Er. S.Thirougnaname and Dr. T.Sundararajan (2013), Studies on Rice Husk Ash Cement Mortar, International Journal of Advanced Research in Engineering and Technology (IJARET), Volume 4, Issue 7, November-December 2013, pp. 25-37.

[7] Roy, S., Shurthi, C. G., Sanjith, J., \& Sudhakar G. N (2018), Mechanical Properties of Concrete Using Optical and Glass Fibre, IOSR Journal of Mechanical and Civil Engineering (IOSR-JMCE), Volume 15, Issue 1 Ver. III (Jan. - Feb. 2018), PP 56-65

[8] James, E. and Howard, B. 1946 "Chemical Composition of Oklahoma-Grown Carrots", Academy of Science for Proceedings of the Oklahoma:93-95. 
Comparative Study on Performance of Cement Mortar Enhanced with Carrot Powder

[9] Elham Abd Al-Majeed, Dalya H. Hameed and Mhmood S. Al Mohnia (2018), The Effect of Palm Kernel Powder on Compressive Strength and Absorption of Portland Cement Mortar, International Journal of Civil Engineering and Technology (IJCIET), 9(10), 2018, pp. 213-223.

[10] Musa, M. and Claude, J. 2007. "Chemical Composition of Carrot Seeds (Darcus carota L.) Cultivated in Turkey: Characterization of the Seed Oil and Essential Oil", Grasas Y Aceites. 58 (4):359-365.

[11] Bao, B. and Chang, K. C. 1994. "Carrot Pulp Chemical Composition, Color, and WaterHolding Capacity as Affected by Blanching”, J. Food Sci. 59(6):1159-1161.

[12] Brett, C. Suddell, F. and Rosemaun, A. 2009. "Industrial Fibers: Recent and Current Developments", Proceedings of the symposium on natural fibers: 71-82. 